\title{
Cimentando relaciones: la materialidad de las carreteras y los espacios públicos en el Perú provincial ${ }^{\star}$
}

Cementing Relations. The Materiality of Roads and Public Spaces in Provincial Peru

\section{RESUMEN}

Este artículo propone analizar cómo el concreto está implicado en la transformación del espacio público en el Perú provincial. Si bien el concreto mejora la capacidad de un estado para producir estructuras confiables y predecibles, también hay límites significativos en relación con su capacidad para la conectividad tanto en el ámbito material como social. La atención etnográfica a la dinámica relacional del concreto revela cómo su promesa de operar como un material genérico, homogéneo $\mathrm{y}$, sobre todo, predecible, se ve constantemente desafiada por la inestabilidad y la heterogeneidad de los terrenos a los que se aplica. La imagen de poder que ofrece el concreto está, por lo tanto, comprometida, ya que la estabilidad y la previsibilidad de esta sustancia sólo es segura si está rodeada e incrustada en relaciones específicas de cuidado.

Palabras claves: concreto, conectividad, construcción, materiales, modernidad, Perú, estabilidad, poder estatal.

\section{Abstract}

This article sets out to analyze how concrete is implicated in the transformation of public space in provincial Peru. While concrete enhances a state's capacity to produce reliable, predictable structures,
Penelope Harvey

Profesora de antropología social en la Universidad de Manchester y codirectora del Centro de Investigación Sobre el Cambio Sociocultural (CRESC) del Consejo de Investigación Económica y Social (ESRC). Ha realizado investigaciones etnográficas en Perú, el Reino Unido y España sobre una variedad de temas (lingüísticos, tecnológicos y de exhibición). Actualmente trabaja en tres líneas de investigación sobre formaciones políticas en el sudeste de los andes peruanos, infraestructura y política de materiales, e imaginarios nucleares.

*El artículo “Cementing Relations. The Materiality of Roads and Public Spaces in Provincial Peru" fue publicado originalmente en Social Analysis, volumen 54, número 2 del 2010. pp. 28-46 y reimpreso en el 2012 en el libro editado por Judith Kapferer Images of Power and the Power of Images: control, ownership and public space. Oxford: Berghahn Books, pp. 28-46. Agradecemos a Berghahn Books el permiso para publicar esta traducción realizada por Daniel Ramírez (ramirezp.daniel@ gmail.com) y Vladimir Caraballo (mvcacuna@gmail.com) (N. del T.).

Cómo citar este artículo:

Harvey, P. (2021). Cimentando relaciones: la materialidad de las carreteras y los espacios públicos en el Perú provincial. Revista de Antropología y Sociología: Virajes, 23(1), 25-47. https://doi.org/10.17151/rasv.2021.23.1.2 
there are also significant limits in relation to its connective capacity in both the material and social domains. Ethnographic attention to the relational dynamics of concrete reveals how its promise to operate as a generic, homogeneous, and above all predictable material is constantly challenged by the instability and heterogeneity of the terrains to which it is applied. The image of power that concrete affords is thus a compromised one, as the stability and predictability of this substance is secure only insofar as it is surrounded by and embedded in specific relationships of care.

Keywords: concrete, connectivity, construction, materials, modernity, Peru, stability, state power.

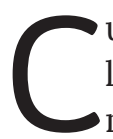

uando comencé a considerar las estéticas del poder estatal, la presencia generalizada del concreto fue lo que llamó mi atención. El concreto, u hormigón, es uno de los materiales que más se utilizan para demarcar y ordenar el espacio público en el Perú contemporáneo ${ }^{1}$. Después de todo, este es un material que aglutina elementos que de otro modo se niegan o no logran adherirse. Durante los últimos 25 años, he visto cómo el uso de este material se extendió desde los centros urbanos más establecidos hasta transformar los pueblos rurales en espacios periurbanos. Donde prevalecieron las estructuras de adobe y los caminos de barro compactado, a mediados de la década de 1980, ahora se encuentran edificios públicos de hormigón, senderos de concreto, carreteras asfaltadas y plazas de la ciudad adornadas con "obras de arte" en concreto, como esculturas, fuentes y bancos (Figura 1).

\footnotetext{
La autora ha profundizado sus reflexiones sobre el concreto en el capítulo "Lithic Vitality: Human Entanglement with Non-Organic Matter" que está incluido en el volumen Anthropos and the Material que coeditó con Christian Krohn-Hansen y Knut G. Nustad en el 2019; en Infrastructures and Social Complexity: A Companion, coeditado con Casper Bruun Jensen y Atsuro Morita en el 2017; y en Roads: An Anthropology of Infrastructure and Expertise, que publicó en coautoría con Hannah Knox en el 2015 (N. del T. a solicitud de la autora).
} 


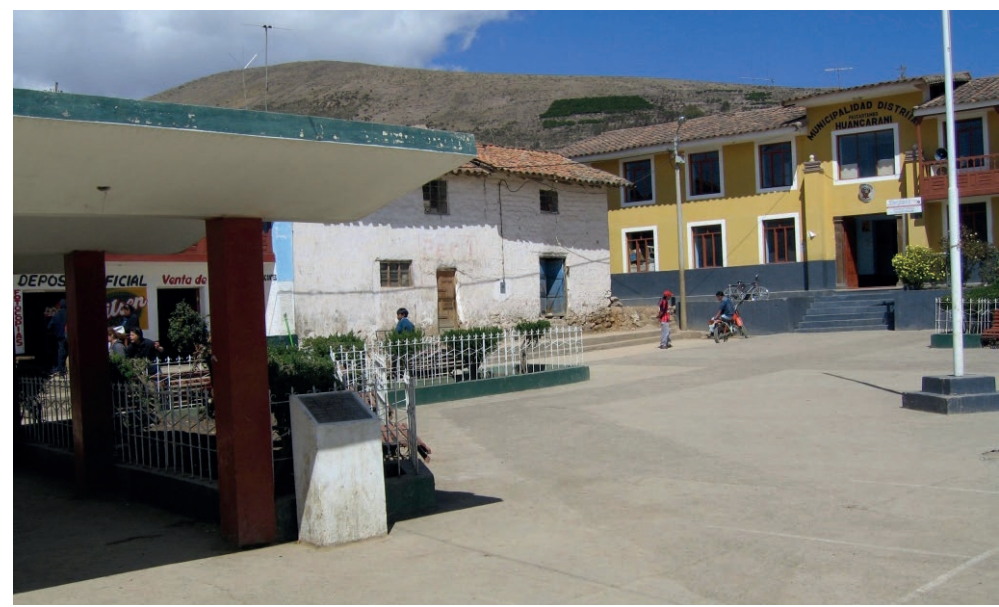

Figura 1. Un nuevo edificio municipal de concreto y la plaza de la ciudad pavimentada.

Fuente: fotografía de la autora, publicada en el original [N. del T.]

Este artículo se propone analizar la seducción del concreto: los valores que se agregan al material y a las formas que se construyen a partir de éste. Aprobado y rechazado con igual pasión en diferentes momentos y lugares, el concreto es una sustancia que tiene una presencia cargada en la historia del ambiente construido moderno. Es el material que entregó los ambiciosos proyectos de vivienda pública y los edificios públicos durante el auge de la construcción después de la Segunda Guerra Mundial, y fue parte integral de las infraestructuras de comunicación (carreteras, puentes y pistas de aterrizaje) que formaron la columna vertebral de la economía moderna del siglo XX (Gandy, 2002). Para muchos, su asociación con el alto modernismo (ya sea capitalista o socialista) lo vincula con opresivas y deshumanizantes arquitecturas de estandarización. Su uso en la construcción masiva de viviendas baratas connota pobreza y malas condiciones de vida. Sin embargo, el concreto siempre ha sido un material con el que los arquitectos e ingenieros han experimentado para producir edificios icónicos, lugares públicos y residencias de lujo (Cohen y Moeller, 2006; Jones, 2006; Wagenaar y Dings, 2005). El hormigón se ha desplegado a gran escala en la arquitectura pública con la intención de perturbar deliberadamente una estética burguesa de la discriminación apelando a la producción en masa y a la forma estándar. Pero también es un material que ha entusiasmado a artistas, arquitectos e ingenieros experimentales, cuyas reputaciones y carreras dependen de estas mismas nociones de distinción creativa. En el mundo del diseño contemporáneo, el concreto emociona porque puede ser moldeado de cualquier forma y porque la apertura de este material a agregados no estandarizados permite la experimentación y resultados innovadores. 
En este artículo, principalmente me interesan las formas en las cuales el concreto está involucrado en la transformación del espacio público en el Perú provincial. Asimismo, me interesa la potencia atribuida a este material, sus capacidades transformadoras y su fuerza seductora. El hormigón está estrechamente vinculado con la industria moderna y el poder estatal contemporáneo, ya que si bien la "piedra líquida" (Cohen y Moeller, 2006) puede tomar inicialmente cualquier forma, ésta es sólo una característica transicional y temporal. El concreto es útil porque combina esta flexibilidad inicial con una poderosa capacidad de fijación, lo que ha llevado a su despliegue ubicuo y dominante en entornos no controlados y en todo tipo de condiciones ambientales. Sus asociaciones con formas estandarizadas que trascienden las especificidades de las condiciones locales le han dado al material un gran valor para regular los espacios del estado moderno.

Han pasado unos 15 años desde que el mercado dominical fue trasladado a su propia área designada en la pequeña ciudad de Ocongate en el sur de Perú, donde he llevado a cabo investigaciones etnográficas desde 1983. Rápidamente el nuevo mercado se convirtió en un espacio regulado, en contraste con la anterior aparición desordenada de puestos de venta, mercancías, comerciantes y clientes que transformaban la plaza que, de otra manera, era bastante somnolienta los domingos por la mañana. La nueva área se construyó con hormigón, se instaló el drenaje, se cubrió una sección central, se designaron puestos, se emitieron licencias y se realizaron inspecciones. Durante el mismo periodo, los edificios de la escuela también se han ampliado considerablemente, pasando de un puñado de estructuras de adobe a mediados de los años ochenta a lo que ahora es un gran complejo de escuelas secundarias y primarias. Cambios similares se pueden ver en relación con el puesto médico, la estación de policía, la central telefónica y, lo más dramático quizás, el propio ayuntamiento. Lo que una vez fue una sola sala de usos múltiples, con un largo balcón de madera que conectaba los asuntos del estado local con la plaza general, ahora es un gran edificio de hormigón en el que está el ayuntamiento con salas funcionalmente diferenciadas: un auditorio, un almacén y un conjunto completo de oficinas ocupado por varios funcionarios que trabajan para el gobierno local, incluido el alcalde, el gerente general, secretarios, agrónomos, ingenieros y educadores.

La aparición del concreto en Ocongate está directamente relacionada con los cambios en el estado local, provocados por los procesos de descentralización asociados con las políticas neoliberales del gobierno descentralizado, que han aumentado considerablemente los recursos fiscales de los municipios locales. Nuevas estructuras de hormigón continúan apareciendo en todo el Perú provincial. De hecho, en el 2006 
mientras viajaba por el departamento de Ayacucho, un área que había sido el epicentro de la guerra entre el estado y la guerrilla maoísta "Sendero Luminoso" - en la que murieron decenas de miles de personas durante la década de 1980-, me sorprendió encontrar pequeñas ciudades en las tierras altas exhibiendo estructuras municipales cada vez más elaboradas en lo que solo podría describirse como una demostración explosiva y competitiva de la grandeza del concreto municipal. Los procesos de descentralización también responden a décadas de demanda popular en relación con una mayor autonomía política y al deseo de los gobiernos municipales de desarrollar una gama de conocimientos técnicos en, por ejemplo, agronomía, turismo y ecología, lo que les permite competir por fondos de fuentes nacionales e internacionales ${ }^{2}$. Por lo tanto, la devolución del poder fiscal al gobierno local ha producido un enfoque altamente diferenciado y más funcional para los asuntos estatales.

Estos nuevos edificios cívicos indexan modos cambiantes de gobierno y se alejan radicalmente de los regímenes de control establecidos dentro de la economía política rural del Perú. El estado peruano poscolonial, establecido en 1824, cedió mucho poder político a los propietarios de las haciendas. Después de la reforma agraria de fines de la década de 1960, el gobierno local pasó a manos de nuevas élites locales: profesionales y comerciantes educados cuya capacidad para representar a la mayoría se articulaba directamente con prácticas racializadas de diferencia de clase. Hoy, sin embargo, es más probable que los municipios estén controlados por hombres jóvenes cuyos padres hubieran sido menospreciados y excluidos por regímenes anteriores. Estos nuevos políticos no han "tomado el poder" de manera directa. El poder de la élite ahora se centra más específicamente en los intereses de capital, que buscan explotar recursos que no están bajo el control del estado local. Los depósitos minerales están en el ojo de la tormenta en estas configuraciones cambiantes de poder. Más del 90 por ciento de los subsuelos peruanos (propiedad del estado nacional) ya están otorgados en concesiones a empresas mineras. La situación es volátil porque los municipios tienen una cierta cantidad de poder político que ejercen, orquestando protestas mientras tratan de "defender" sus territorios y el uso tradicional de la tierra en apelaciones a campañas internacionales de derechos humanos y medioambiente. Es en este escenario donde aparece ahora el concreto, llevando consigo una promesa muy ambigua y compleja.

\footnotetext{
Estas ideas sobre las relaciones municipales, regionales y del gobierno central están integradas en largas conversaciones con Deborah Poole, con quien elaboramos una propuesta de investigación sobre el estado regional peruano. La investigación la realizamos, después de publicado este artículo, entre el 2010 y el 2013, con financiamiento del Consejo de Investigación Económica y Social (ESRC, por sus siglas en inglés) y el Consejo de Investigación de Ciencias Sociales (SSRC) a través de una beca de colaboración desarrollada en el Centro de Investigación sobre el Cambio Sociocultural (CRESC) en la Universidad de Manchester. [Esta nota ha sido actualizada a solicitud de la autora, N. del T].
} 
El control de los cargos públicos por parte de un nuevo sector de la población es un cambio importante que tiene ramificaciones aún por definir en la escena nacional e internacional. Pero la ubicuidad del concreto responde no sólo a la necesidad de un espacio más diferenciado y orientado burocráticamente para el ejercicio del gobierno local. A medida que más y más áreas de la vida cotidiana se diferencian y financian dentro de estos nuevos regímenes, los funcionarios locales no sólo son responsables del desarrollo local, sino también del dinero que se gasta. En un contexto de escasos recursos, un servicio civil politizado y, más significativamente, en una dinámica arraigada de conflicto y desigualdad, los funcionarios locales están muy limitados con respecto al dinero que pueden gastar de manera segura. Deben proporcionar empleos a la población local, actuar de manera que produzcan resultados visibles y "mejoras", y emprender proyectos a corto plazo que se puedan entregar durante el transcurso de su período en el cargo. El concreto es un gran aliado en tales circunstancias. Es barato, maleable y duradero, y tiene fuertes resonancias simbólicas con mejores y más civilizadas formas de vida que sirven para reforzar la credibilidad de esta nueva generación de funcionarios estatales locales ${ }^{3}$.

Sin embargo, los efectos sociales del concreto pueden ser de largo alcance, a veces de manera inesperada. Cuando comencé a vivir en Ocongate a mediados de la década de 1980, la plaza central se construyó sobre tierra compactada y endurecida. A fines de la década de 1990, la tierra había sido cubierta con concreto, y la plaza ahora es más adecuada para el tráfico motorizado y es más limpia en relación con los pequeños restaurantes y puestos que venden comida y bebida a los viajeros. Pero uno de los cambios silenciosos, inadvertido hasta donde sé, se relaciona con el potencial ritual de este espacio en el corazón de la aldea. En el pasado la plaza era el sitio de muchas ceremonias y rituales públicos. Algunos de estos continúan como antes, pero algunos ya no se celebran, particularmente aquellos que se refieren más directamente a las fuerzas de la tierra y a la profunda relación entre los agricultores y los elementos de los que dependen, especialmente la tierra y el agua.

Las corridas de toros locales son un ejemplo interesante. Las corridas de toros son festivales patrocinados por el estado, que se celebran dos veces al año (Harvey, 1997). Los jóvenes del pueblo solían instar a los ganaderos del interior a que trajeran sus toros a la aldea para la lidia, y contrataban especialistas en rituales para que atrajera a estos eventos a un cóndor desde

Ver Orlove (1998) y Colloredo-Mansfeld (1994) para discusiones detalladas sobre el valor relativo de las estructuras de tierra (ladrillos de adobe, caminos de tierra, ollas de barro) y concreto. Ambos autores destacan los valores ambiguos pero dicotomizados que estos materiales transmiten en los Andes. 
la montaña nevada de Ausangate. En estas ocasiones, el centro de la ciudad era entregado a aquellos sectores de la población que tenían menos probabilidades de controlar este espacio cívico. Como en los rituales clásicos de la reversión, la ciudad se revitalizó a sí misma a través de la promulgación de un ritual ficticio de un poderoso compromiso, pero finalmente alegre, entre las fuerzas del paisaje animado y el estado local. Además, en este ritual el ayuntamiento aparecía como el cuerpo que integraba a la región. Cada uno de los cuatro ayllus, o grupos comunitarios/parentales/territoriales amplios que representan a las poblaciones rurales del distrito, se encargarían de cerrar secciones de la plaza, para retener efectivamente a los toros y al cóndor en el corazón del pueblo durante la corrida. Una vez que la plaza fue pavimentada, ya no era seguro mantener la lidia allí. Los dueños de los toros guardan celosamente el bienestar de sus animales. Los toros y los cóndores no deben ser dañados en estos encuentros, sostienen; son los jóvenes los que deben tomar el riesgo, aquellos que buscan el compromiso. La pavimentación de la plaza coincidió así con un sutil alejamiento de un evento que representaba la exhibición cargada de interdependencia entre las élites educadas y aquellos más estrechamente relacionados con las fuerzas del entorno local. En el nuevo coliseo la corrida de toros se ha transformado silenciosamente en un espectáculo folclórico.

Luego hay transformaciones radicales y deliberadas, como las relacionadas con la carretera asfaltada de dos carriles que se está construyendo actualmente para conectar la, relativamente boyante, economía de exportación de Brasil con los atractivos mercados de China a través de los puertos del Pacífico peruano ${ }^{4}$. Este proyecto de construcción es una importante colaboración internacional, respaldada por recursos de bancos internacionales de desarrollo. Resultado de una gran inversión de capital, esta franja de concreto asfáltico que ahora conecta la ciudad de Ocongate con la capital departamental de Cusco hace un tipo diferente de distinción. Las coordenadas temporales y espaciales del estado peruano se reconfiguran ahora por el cambio en los modos y velocidades de conectividad que esta carretera ofrece. Hace diez años, en un día bueno, el tiempo de viaje era de aproximadamente de 10 horas. La ciudad capital está ahora a solo 2 horas de distancia, lo que permite a los funcionarios y servidores públicos ir y venir con facilidad. Por lo tanto, existe una presencia estatal más continua en la ciudad y las obras públicas son un componente poderoso de esta actividad local del estado. Sin embargo, la apertura de esta ciudad a otras modernidades en curso también ha generado la demanda

Con mi colega Hanna Knox, estoy realizando investigaciones en esta carretera, la Carretera Interoceánica. Estamos agradecidas por la financiación de CRESC y por una subvención adicional del ESRC, los cuales han subsidiado el trabajo de campo para este proyecto. [En el 2015, resultado de esta investigación, las autoras publicaron el libro Roads: An Anthropology of Infrastructure and Expertise. Ithaca: Cornell University Press. N. del T.] 
de una relación más adecuada y satisfactoria con el estado moderno. A través del nuevo personal empleado por el ayuntamiento, la experticia técnica podría estar disponible más fácilmente; pero al mismo tiempo, esa "experticia" se ha vuelto algo menos convincente y menos confiable.

El concreto ofrece una forma de explorar estas dinámicas. Es una sustancia que une las promesas materiales e ideológicas de la modernidad y también nos permite observar cómo y dónde aparecen las fracturas. En la siguiente sección del artículo, exploro el potencial social del concreto a través de un estudio de caso de la pequeña ciudad amazónica de Nauta. Luego giro la mirada para ver con más detalle la materialidad del concreto en sí mismo: las demandas que hace y las relaciones en las que involucra a los ingenieros que son contratados para entregar proyectos estatales. Finalmente, en las conclusiones, planteo algunas preguntas con respecto a cómo estos entendimientos de los complejos enredos de lo técnico y lo político podrían modular nuestras percepciones del orden social del estado y la concreción del poder estatal.

\section{La potencialidad social del concreto: modismos de conectividad y modernidad}

Nauta, un pequeño pueblo en el norte de la Amazonía peruana, ha anhelado la modernidad durante la mayor parte del siglo. La gente local cuenta que el pueblo fue engañado en su destino por el inconstante movimiento del poderoso río del que depende toda la actividad comercial. En los años 30, Nauta se convirtió en el centro de la creciente zona de comercio en las fronteras de Brasil, Ecuador y Colombia, pero de repente se encontró varado por el barro empalagoso y las arenas movedizas que impidieron el desarrollo de su puerto cuando el río cambió de curso. A solo 100 kilómetros al sur de la pujante ciudad de Iquitos, un lugar que ha prosperado debido al declive del poblado, la gente de Nauta ha llevado a cabo una larga campaña para crear y mantener un espacio cívico abiertamente moderno en la selva.

Los turistas que pasan por Nauta no suelen impresionarse por el ambiente polvoriento, somnoliento y muy concreto (Figura 2). La vegetación forestal amenaza con irrumpir en todos los puntos a pesar de un intento abierto de mantenerla a raya. La plaza central hace algunas concesiones a la noción de un "ambiente de jardín", con árboles y plantas que proveen sombra y color, pero en otros lugares el concreto está prácticamente sin ornato. Es como si los residentes de Nauta, resuelta y muy gradualmente, hubieran urbanizado todo lo que pudieron en su entorno inmediato mientras esperan la carretera que eventualmente los conectaría con Iquitos. Algunas de estas modificaciones aún no se han utilizado. Hay concreto, pero gran parte está 
en espera. Por ejemplo, un nuevo mercado de pescado ahora se encuentra junto al río en un área que podría convertirse en el nuevo muelle, y aún no ha sido abierto. Y junto al viejo muelle, está la nueva caseta de información turística, que todavía no ha recibido a ningún turista.

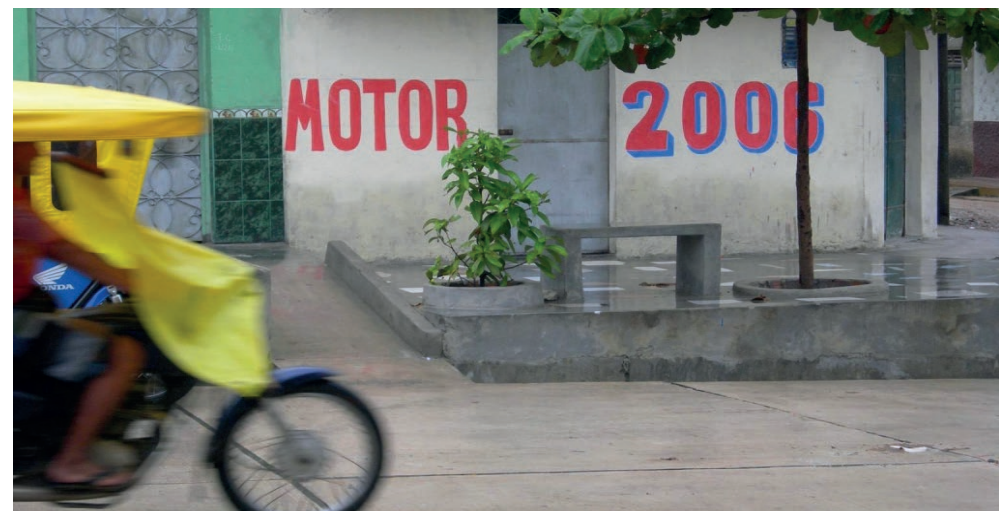

Figura 2. Concreto en Nauta.

Fuente: fotografía de la autora, publicada en el original [N. del T.]

Caminos de concreto conectan el centro de Nauta con las áreas periféricas del pueblo (Figura 3). En algunos lugares casi se puede sentir que la selva lo rechaza cuando aparecen grietas y protuberancias con una velocidad alarmante después de que se aplica el hormigón. Este material omnipresente, pero de alguna manera insuficiente, puede decepcionar a los ambientalistas y modernizadores por igual. Los ambientalistas siguen siendo testigos de la brutal imposición de valores y materiales externos y perjudiciales, mientras que los modernizadores se sienten frustrados por la fragilidad de la capa de concreto que nunca logra frenar por completo las fuerzas de la selva.

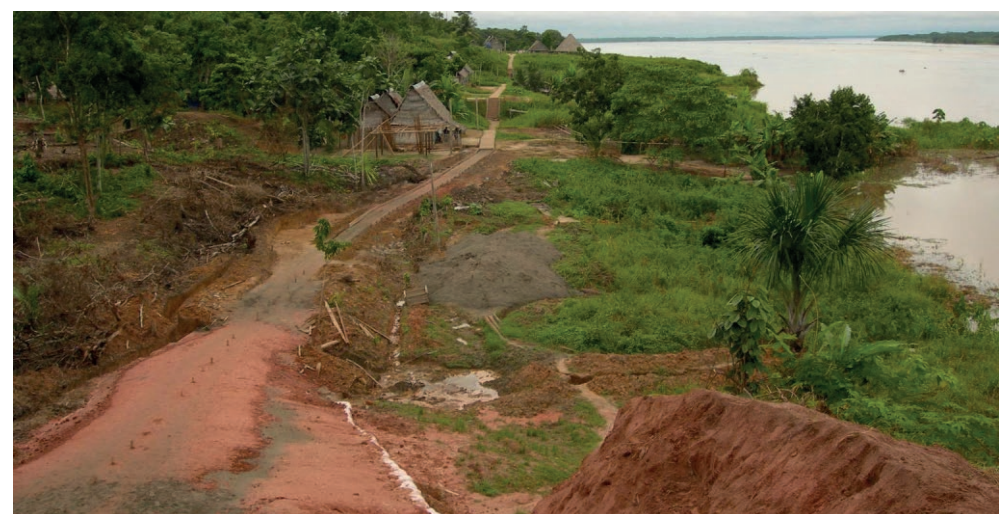

Figura 3. El concreto moviéndose en las zonas periféricas.

Fuente: fotografía de la autora, publicada en el original [N. del T.] 
No obstante, el hormigón proporciona una superficie relativamente estable, una posibilidad de movimiento y conectividad. Ofrece un mínimo de previsibilidad y refuerza las aspiraciones de nuevos mercados, para un futuro en el que los turistas y comerciantes puedan revivir la economía estancada de la ciudad. Y en ninguna parte se sintió tan profundamente esto como en Nauta, donde los residentes habían estado esperando la carretera por más de 70 años, según me dijeron cuando fui por primera vez en 2005. Específicamente, en esta área, la carretera era deseada como una forma de alejarse del río que los había traicionado. El río Amazonas, que comienza donde el Ucayali se une al Marañón a sólo 1 kilómetro al sur de Nauta, es una fuerza enérgica e impredecible que desafía el control. Se sabe que el transporte fluvial es peligroso y poco confiable, y aquellos que navegan tienen que aprender las formas y los caprichos del río. Incluso las potentes embarcaciones motorizadas requieren un manejo hábil para lidiar con escombros que se mueven rápidamente, corrientes cambiantes y chubascos repentinos. En la década de 1980, el presidente peruano Belaúnde Terry fue falsamente ingenuo cuando declaró que los ríos eran las autopistas del oriente de Perú. Estas vías fluviales ciertamente proporcionan una red de comunicaciones efectiva para los pueblos de la selva. Sin embargo, los subsecuentes ambiciosos planes de Belaúnde para construir la Carretera Trans-Amazónica permitieron que los campesinos andinos sin tierra colonizaran los territorios orientales del estado, reconociendo implícitamente con esto que las redes de transporte que requieren experiencia y habilidad son incompatibles con el tipo de transformación social radical que él estaba maquinando.

En este ambiente de selva tropical, el concreto a menudo no cumple con su promesa de estabilidad y fuerza. Así como los residentes observaban que la carretera aparecía lentamente, también atestiguaban cómo este material, supuestamente predecible y autónomo, continuamente era socavado por las complejas y tensas relaciones en las que estaba envuelto. La historia de la emergencia de esta carretera es larga y compleja. Hubo otros giros y vueltas del destino más allá del abandono original del río, incluidas las fluctuaciones en los mercados internacionales, las guerras fronterizas con Ecuador y un estado central débil que buscó favores de las autoridades regionales ricas en petróleo. Pero en el 2005, después de varios comienzos falsos y una justa medida de incompetencia y criminalidad, el tramo de 100 kilómetros que conectaba Nauta con Iquitos estaba casi terminado. El gobierno central había proporcionado los fondos decisivos para terminar el trabajo. Vi cómo la última compañía de construcción, en una extensa lista, intentaba completar las obras. Los últimos 5 kilómetros eran todo lo que quedaba, y este tramo estaba en disputa. El gobierno regional había iniciado procedimientos legales contra 
el contratista, que era un consorcio compuesto por varias empresas subcontratadas. El problema era que la superficie ya se estaba rompiendo. Una mujer se quejó de que simplemente se estaba desmoronando, "como un pastel". Los materiales fueron confiscados y la gente de Nauta esperó la resolución. Un año y algunos meses después de que la carretera estuvo totalmente terminada, fuimos a hablar con el ingeniero que había dirigido la fase de finalización del proyecto. Nos habló de sus "problemas" con esa obra y de sus temores respecto de que, esta vez, la superficie tampoco duraría. Pero esta vez, en lugar de citar la mala práctica y la corrupción de los contratistas anteriores, bromeó sobre los "salvajes", la gente común que no sabía cómo cuidar lo que tenía. Él había conducido por la carretera para documentar las diversas formas en las cuales la negligencia cotidiana perjudicaba la superficie que había cubierto. La gente del pueblo estaba anteponiendo efectivamente sus propias necesidades mundanas a las necesidades de la superficie de la carretera, bloqueando las zanjas de drenaje con cargas pesadas sobre ellas o al no eliminar los escombros acumulados.

Esta breve descripción de las superficies de concreto en un pueblo de la Amazonía muestra cómo la atención a este tipo de espacios puede revelar los trazos materiales de las intervenciones y la retirada del estado. Nuestras investigaciones sobre los antecedentes de la carretera de Nauta abrieron las historias de incursión en la zona, los primeros intereses comerciales y fiscales en relación con el auge del caucho del siglo XIX, la llegada del ejército nacional para proteger la frontera con Ecuador, la lucha para extraer valiosas maderas duras, las campañas para establecer parques nacionales y reservas naturales, la llegada y salida de compañías petroleras, el desarrollo gradual de las instalaciones de infraestructuras estatales y el creciente número de casas y pequeños asentamientos a lo largo de la carretera emergente. Esta obra, por lo tanto, no era simplemente otro ícono de la presencia opresiva del estado, equivalente a las estructuras impuestas de hormigón como la iglesia, el banco y la prisión que Taussig ([2004] 2013) describe en relación con los pueblos pequeños de Colombia. En Nauta, el hospital, la escuela, el ayuntamiento y la oficina de correos fueron manifestaciones de presencia estatal que, como la carretera en sí misma, fueron activamente solicitadas por la población local.

A pesar de esto, como sugerí anteriormente, el "orden social" de Nauta y su integración en estructuras estatales más amplias sigue siendo insatisfactorio para la mayoría de los residentes. Para algunos, la conectividad todavía es inadecuada ya que la nueva carretera ha vaciado al poblado de las clases profesionales relativamente ricas que 
ahora pueden viajar con facilidad a la ciudad de Iquitos. Y mientras que la mayoría de los maestros y trabajadores de la salud ya no viven en Nauta, los turistas todavía no han llegado. No hay infraestructuras seductoras de lugares cómodos pero exóticos para los viajeros adinerados que desean alejarse del concreto y entrar en otro tipo de espacios más ecológicos y controlados adentro de la selva. Las condiciones han mejorado para aquellos que buscan extraer recursos de la región. Ahora es más fácil que antes llegar y extraer maderas duras, vender carbón vegetal y llevar al mercado productos agrícolas y forestales escasos. Pero estos comerciantes se encuentran en un conflicto abierto con los ambientalistas y las campañas respaldadas internacionalmente que intentan proteger la flora y la fauna de la selva que la carretera ha hecho vulnerable.

El concreto manifiesta así un poder inestable. Sin duda, en la superficie notamos la reconfiguración visible de los espacios públicos en los pueblos pequeños. Pero ni en el Amazonas ni en los Andes encontré personas particularmente satisfechas con lo que habían recibido más allá de los discursos retóricos realizados al momento de develar una nueva estructura.

De vuelta en Ocongate, la gente decía que el cóndor de hormigón que decora el centro de su plaza se parece más a un pollo. La estatua no logra conjurar el majestuoso pájaro que solían bajar de la montaña para participar en las corridas de toros. Aún así, también vale la pena señalar que no existe una tradición indígena de producción de este tipo de representaciones. Las representaciones que las personas sí hacen son miniaturas que a menudo, pero no necesariamente, exhiben gran precisión. Estas miniaturas hoy en día se producen más comúnmente como modelos de arcilla en el contexto de los llamamientos a los poderes de la tierra para que atraigan la buena fortuna. Idealmente, el modelo funciona como un prototipo que puede ayudar a generar lo que representa (Allen, 1997). Hay una larga tradición de miniaturización en los Andes en la que se entiende que el modelo condensa la fuerza y la energía vital de lo que se representa. Los Inca, por ejemplo, solían plantar en sus campos miniaturas de mazorcas de maíz elaboradas con oro, y hechas a mano, para extraer una rica cosecha dorada de la tierra ${ }^{5}$. Los guijarros y las pequeñas piedras, que junto con la tierra compactada constituyen los caminos y senderos por los que la gente viaja diariamente, son condensaciones del gran poder de la cordillera de los Andes (Allen, 1997). El fracaso del cóndor de hormigón tiene una resonancia adicional: no solo falla como imagen decorativa, sino que se ve claramente que no activa ninguna energía

Para una discusión más detallada de este tema ver Harvey y Knox (2009). 
vital. El concreto del que está hecho aparece como materia inerte, y la decepción comprensible se relaciona con el recordatorio de que esta estatua siempre es menos que lo que pretende retratar o invocar. Ocurre un efecto paralelo en relación con muchos proyectos de desarrollo, que producen escepticismo general con respecto a la percepción de los beneficios para la población local. Para algunos, incluso existe la sensación de que el pueblo ha sido marginado de alguna manera por el camino que ahora bordea uno de sus límites. A pesar de la nueva conectividad, se hace evidente que lo más importante es quién viaja, a dónde y por qué motivo. Muchas personas se sientan y miran mientras otros pasan a toda velocidad en sus lujosas camionetas. Estos viajeros ya no necesitan comprar cosas localmente, ya que ahora no están lejos de la gama más amplia de bienes y servicios disponibles en la ciudad.

Hasta el momento, he sugerido que el concreto media las relaciones entre la sociedad civil y el estado. Éste propicia los lugares donde se reúnen las personas y los funcionarios estatales, designa sitios saludables e higienizados para el comercio, y promete eficiencia, confiabilidad, neutralidad y modernidad. Todas estas cosas parecen funcionar en otro lugar y para los demás, pero no funcionan del todo en el aquí y el ahora de las personas con las que hablé en Nauta y en Ocongate. Quizás esto se conecta con el sentido en que el concreto es literalmente una forma superficial y, como tal, parece impedir un compromiso más profundo con las relaciones y los problemas que éste debería resolver. La vulnerabilidad de los técnicos locales y los titulares de cargos estatales en relación con estas obras públicas es expuesta, ya que en sus intentos por hacer visibles su actividad e intervención también revelan su incapacidad para marcar la diferencia. La imagen del gobierno local se ve empañada por las inevitables acusaciones de corrupción e ineptitud. Sin embargo, el atractivo duradero del concreto está firmemente alojado en su promesa de resistencia y estabilidad. En la siguiente sección, considero la potencialidad material del concreto y sus capacidades y límites en relación con las imágenes de poder.

\section{La potencialidad material del hormigón: agregación y proceso}

El concreto es un material compuesto hecho de la mezcla de cemento, agua y agregados, que generalmente son arena y piedra triturada. Los aditivos adicionales pueden aumentar la resistencia del concreto al reducir la cantidad de agua requerida. La resistencia relativa del producto final dependerá de la relación entre cemento y agua y del tipo de agregado utilizado. Los procesos de mezcla por lo tanto son cruciales y requieren un control estricto, ya que los contaminantes afectarán el resultado final. 
La pureza de los agregados es estrictamente controlada ya que la materia orgánica que se introduce con la arena y las piedras afectará negativamente la resistencia y la fiabilidad de toda la mezcla. El agua también debe tener un nivel de pureza confiable y constante.

La particularidad del hormigón como material de construcción se deriva principalmente de la reacción química producida al mezclar cemento y agua, que produce un proceso irreversible de endurecimiento gradual. De hecho, es esta característica de endurecimiento en el agua lo que hace que el cemento sea indispensable para muchos proyectos de construcción. Esta relación entre el cemento y el agua puede parecer contraria a la intuición en contextos donde la mayoría de los materiales de construcción sólidos adquieren su resistencia y durabilidad mediante un proceso de deshidratación. En la región andina, las técnicas de deshidratación han sido fundamentales para la comprensión local de la vitalidad almacenada. Los Inca son reconocidos por sus prácticas de momificación mediante las cuales la vitalidad de los muertos fue preservada y reactivada a través de la libación ritual, y donde los ciclos anuales de lluvia y sequía marcaron la liberación y la retención de las fuerzas vivificantes (Gose, 1994). En los tiempos contemporáneos, estas técnicas todavía se usan para el almacenamiento de papas y carne, que se desecan, almacenan y rehidratan para liberar sus energías como alimento. En su libro Mi museo de la cocaina, Michael Taussig ([2004] 2013) tiene un capítulo titulado "Cemento y velocidad" en el que reproduce una maravillosa caracterización del cemento, sus cualidades y capacidades, así como los procedimientos básicos de su producción ${ }^{6}$. Él señala que la relación interesante y contraria a la intuición entre el cemento y el agua se conoce desde la antigüedad, aunque el material se entendió en términos muy diferentes y a través de relaciones muy diferentes a las de hoy. Taussig reproduce el relato de Vitruvio, un arquitecto y constructor romano del siglo primero cuyo nombre está estrechamente relacionado con la primera documentación de la naturaleza del concreto:

Vitruvio [...] dijo que la piedra estaba compuesta por cuatro elementos: aire, tierra, fuego y agua. Como constructor quería una sustancia como la piedra, pero maleable (...) No era suficiente quebrar la caliza en piedras pequeñas y mezclarlas con arena porque no había unificación ni endurecimiento. Eso sólo podría ocurrir con un calor intenso, que dejaba porosa la roca (cita fuentes antiguas):

Originalmente publicado en inglés como My Cocaine Museum. Fue traducido y publicado por la Universidad del Cauca en el 2013; el capítulo señalado por la autora en el original es "Cement \& Speed" y el texto de la cita es de la traducción con la correspondiente paginación; los corchetes "[]" son nuestros y los paréntesis "()" acotaciones de Harvey. (N. del. T) 
"El agua y el aire, por lo tanto, que están en la sustancia de las piedras, siendo descargados y expulsados y sólo quedando el calor latente, recuperan su vigor después de ser repuestos con agua, que repele el fuego, y el agua que entra en las rendijas ocasiona una fermentación; así la sustancia de la cal es refrigerada y el calor superabundante expulsado". (Taussig, [2004] 2013, p. 175)

Los constructores e ingenieros siempre han atendido a las capacidades de los materiales específicos. El concreto fue valorado por su cualidad de negociar las tensiones entre la materia sólida y la fluida, pero ésta tuvo que ser nutrida y extendida desde la relación potencial más básica de sus elementos constituyentes. Una resolución exitosa requería la promulgación o materialización de una teoría del cosmos en la cual el poder de los gobernantes divinos estuviera necesariamente implicado. El modelo de integración presocrático que describe Taussig se refiere a la comprensión alquímica de la materia, donde el desafío para el constructor era saber cómo activar los materiales adecuadamente. Como se discutió anteriormente, la atención a las propiedades vitales de la materia era igualmente importante para los constructores del imperio incaico. Al igual que los romanos, los Inca fueron un poder imperial que invirtió mucho en la construcción de caminos y en la construcción estatal de palacios y templos monumentales. Los gobernantes ejercieron el poder divino, pero lo hicieron en conjunción con la avanzada experimentación científica premoderna. En el presente, los Inca son reconocidos por su arquitectura duradera y específicamente por su capacidad para erigir estructuras monumentales trabajando la piedra con tal precisión que no necesitaban usar mortero ${ }^{7}$. Sin embargo, el punto que quiero enfatizar aquí es simplemente que, ya sea que estemos hablando de piedra o mortero, estos materiales fueron tratados como entidades vitales que requieren un compromiso hábil, a menudo ritualizado, así como una gran inversión de recursos y mano de obra, por lo que la fina piedra de los Inca también es famosa. Por lo tanto, las estructuras revelan no sólo la capacidad política de controlar a otras personas, sino también la capacidad de moldear y acomodarse a las fuerzas de la materia que finalmente contuvieron y manifestaron el poder del estado incaico.

En relación con estas consideraciones, es más fácil ver cómo la afirmación de que el cemento fue "inventado" en el siglo XVIII podría ser

\footnotetext{
Me hizo gracia encontrar el siguiente comentario de la presidenta del American Concrete Institute en el contexto de un informe a la industria sobre su visita a América del Sur (Coke, 1999): "Una visita a Perú no estaría completa sin dedicar un tiempo a Machu Picchu, las ruinas de la última ciudad Inca, en la cima de una montaña en los Andes. Pero esa es otra historia, y las ruinas no son de concreto. En realidad, no se utilizó mortero en absoluto, ipero ni siquiera se puede pasar una tarjeta de presentación entre las piedras!".
} 
realmente creíble. Chandra Mukerji (2006) ha disputado con razón esta afirmación, demostrando que el concreto era claramente conocido, utilizado y suministrado en Francia e Italia durante el siglo XVII. Sin embargo, ella también nos dice que el conocimiento de estos materiales pertenecía a los gremios calificados y secretos de los constructores artesanales y, además, que tal conocimiento era explícitamente desconfiado en los círculos de élite. Ella describe un momento de tensión fascinante entre la corte, los gremios de artesanos y los nuevos técnicos de los campos emergentes de la ingeniería profesional y la ciencia experimental. Los fundamentos literarios y cortesanos de la ciencia moderna contribuyeron a cortar el vínculo entre el conocimiento científico y el vernáculo, y aunque este resultado fue decididamente inestable en la Francia del siglo XVII, la Inglaterra del siglo XVIII proporcionó un escenario muy diferente. Aquí, en el contexto de la producción industrial emergente, el concreto podría alejarse definitivamente de las asociaciones ocultas con el conocimiento alquímico para formar la base de lo que se convertiría en un material axiomáticamente moderno, producido en masa y estandarizado, uno que fuera predecible y evidente en sus propios términos, ya no requiere el tipo de atención que habría sido necesaria en la antigua Roma ${ }^{8}$.

Peter Jones ofrece una descripción estándar de la "invención" del cemento moderno que respalda el punto de Mukerji:

La química del hormigón era, por supuesto, desconocida para los romanos, pero ellos sí sabían que pequeñas variaciones en la mezcla alteraban su fuerza...La puzolana era bien conocida por los arquitectos franceses del Renacimiento, quienes la recomendaban para cimientos en agua o suelo pantanoso y los sustitutos puzolánicos... fueron comúnmente usados en el norte de Europa desde el siglo XVII en adelante. Pero los desarrollos más rápidos tuvieron lugar durante el siglo XIX, después de la publicación en 1791 de las investigaciones sobre morteros que Smeaton sostenía desde finales de la década de 1750 sobre morteros. La fabricación de cementos artificiales quemando materiales a temperaturas más altas, desde la década de 1820, aceleró el desarrollo del concreto moderno; el más conocido de ellos fue el "cemento Portland", inventado en 1824, que pronto se convirtió en la base de las mezclas de cemento y concreto. (Jones, 2006, p. 24-25)

8 Ver Bensaude-Vincent y Stengers (1996) para un relato fascinante del surgimiento de la química moderna como una práctica que cuestionó constantemente sus fundamentos, su conocimiento, sus prácticas y su estatus: una historia de aventuras intelectuales en lugar de una empresa singular con un único telos. 
Por lo tanto, si bien el cemento era conocido y utilizado desde la antigüedad, fue efectivamente "reinventado" como producto del conocimiento químico moderno en el siglo XVIII. En el proceso se convirtió en un tipo diferente de material, entendido para manifestar poderes relacionales muy diferentes al concreto de la antigua Roma o de la Francia del siglo XVII.

El contexto industrial de la producción de cemento es crucial para las imágenes de poder que este material proyecta en el ambiente contemporáneo peruano. La industria del cemento requiere altos niveles de inversión de capital en extracción de minerales, producción en fábrica y transporte del voluminoso y pesado producto terminado. Esta es una industria en la que las compañías que operan en economías de escala pueden obtener grandes ganancias; por lo tanto, tiende a haber poca competencia (Dumez y Jeunemaître, 1998). A principios del siglo XXI, el 96\% peruano era producido por sólo cinco empresas (Gurmendi, 2001). Un siglo antes, esta tendencia a la concentración favoreció a los productores de Europa y Estados Unidos. Los intentos de los empresarios europeos por situar la producción en América Latina (originalmente en Cuba y posteriormente en Brasil y Argentina) no lograron despegar debido a las dificultades que enfrentaron para elaborar un producto competitivo y suficientemente "uniforme". La industria creció a lo largo del siglo XX en relación con la creciente demanda de concreto generada por los programas de desarrollo respaldados por el estado, y fue impulsada por la intervención de Estados Unidos después de la Segunda Guerra Mundial. La industria del cemento en Perú tardó en surgir: las primeras fábricas sólo entraron en producción hasta 1922 (Tafunell, 2007).

Lo más significativo, en relación con el análisis en curso, es que el cemento es un producto industrial que estaba completamente vinculado con el capital extranjero y la experticia tecnológica cuando apareció en las primeras décadas del siglo XX. Su producción estuvo directamente relacionada con el desarrollo de infraestructuras estatales y la construcción de economías nacionales. De hecho, existe una correlación directa entre el tamaño de la industria del cemento en los estados latinoamericanos, los índices relativos de pobreza y el nivel de inversión estatal en obras públicas. En Perú, que nunca compitió con las economías de Brasil, México y Argentina, el concreto era un material esperado, un material que impulsó poderosamente la inversión estatal, la modernización y la prosperidad (Tafunell, 2007).

Hasta ahora, mi discusión se ha centrado en cómo el concreto, esta piedra maleable, ha sido y continúa siendo desplegado por los estados 
modernos para manifestar una presencia duradera, una capacidad técnica y una ambición modernizadora y transformadora. La alusión de Taussig ([2004] 2013) al concreto de la antigua Roma nos recuerda, sin embargo, que tales proyectos requieren constructores, personas con teorías y conocimientos del mundo social y material que ellos buscan transformar. En la sección anterior, sostuve que personas de todos los ámbitos de la vida en Perú acogen activamente el concreto en sus mundos como una manifestación de la capacidad y del cuidado del estado. Sin embargo, también es cierto que los minerales y las arcillas que se combinan en la producción de cemento -así como el agua, la arena y las piedras que se agregan para producir el concreto- están lejos de ser sustancias neutras en el mundo andino; al contrario, las personas luchan por integrar al concreto con las comprensiones existentes del mundo material y sus relaciones inherentes.

El concreto es un material que merece atención, pero los pueblos andinos no lo entienden como una forma de materia que se basa en los principios cosmológicos fundamentales que consideran que la tierra, las rocas y las montañas son una fuente de energía vital. Es en este sentido que el concreto se convirtió en una sustancia propiamente moderna y técnica, logrando la dimensión más mágica del hecho material: la exclusión de su sociabilidad inherente. Sin embargo, estas dimensiones tienen la costumbre de reaparecer en las prácticas mundanas de construcción e ingeniería. La cuestión de los componentes del concreto tiende a no presentarse en pequeños proyectos de construcción, ya que estos emplean cemento premezclado que llega de otra parte, embalado y completamente separado del entorno vivido. En estas circunstancias, el concreto puede sostenerse por sí mismo. Su procedencia industrial rompe con éxito los lazos con otros tipos de materias. Sin embargo, en el contexto del importante proyecto de construcción de carreteras mencionado anteriormente, el estado necesitaba reunir sus propios recursos y unir en el sitio los agregados para la producción de concreto y asfalto. En el proceso, no se trata simplemente de que se revelen los componentes, sino de que su fuente también sea identificable. De esta manera, se hicieron explícitas las reivindicaciones en pugna de las diversas materialidades.

En Ocongate, existe una grave preocupación por el río que corre a lo largo de la ciudad. El río tiene su origen en Ausangate, la montaña nevada que domina el paisaje local y se considera una de las fuerzas espirituales más poderosas de la región. La gente local cree que la vitalidad de la tierra y de toda empresa humana depende de la fuerza de esta montaña. El estado peruano sostiene que es dueño de todos los cursos de agua y ha dado permiso a la empresa constructora para dragar 
el río en busca de arena y piedras. Tanto el río como la montaña han reaccionado a este proceso. Según algunos, las nieves de la montaña están retrocediendo en proporción directa a los flujos de tráfico. El río, sometido a un violento proceso de extracción que es literalmente doloroso para la gente, se ha vuelto irreconocible (Figura 4). La gente local ahora cuestiona las relaciones que el proceso de extracción ha hecho explícitas: ¿De quién es la piedra? ¿De quién es el río? ¿Cómo se los han arrebatado a las autoridades locales? ¿Cuál es la relación entre el estado local y el estado nacional? ¿Qué papel juega el estado regional para atravesar estas tensiones? ¿Cómo se identifican, ubican y canalizan estos recursos?

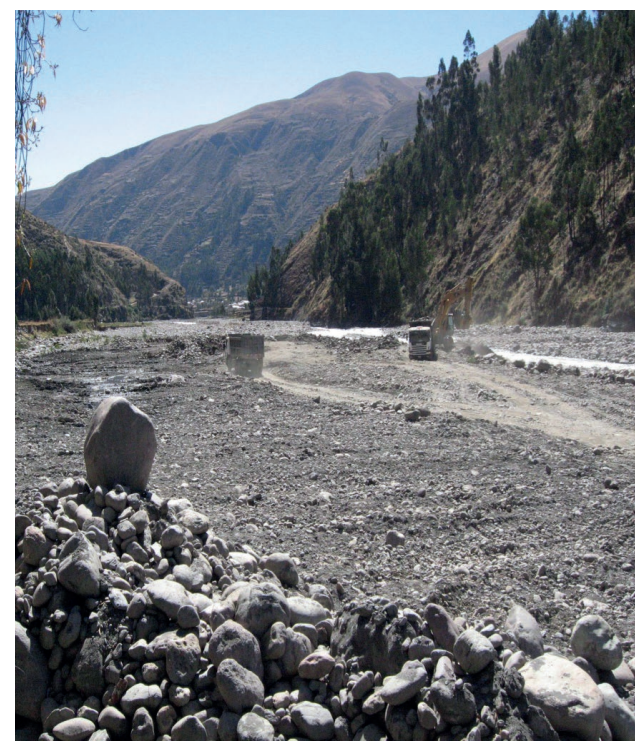

Figura 4. Extracción de piedras del río.

Fuente: fotografía de la autora, publicada en el original [N. del T.]

En el caso de la carretera de Nauta, surgió un problema similar. Encontrar piedra es uno de los dilemas clave para la construcción de carreteras en la región Amazónica. La empresa constructora había identificado una posible fuente local y, a través del Estado, había establecido su derecho a extraer el material. Sin embargo, la gente se opuso tan fuertemente que la compañía calculó que sería mayor el costo en seguridad, reparación y tiempo de negociación que ir más lejos. Finalmente, la piedra para el camino de Nauta fue traída de un sitio ubicado a siete días río arriba, una situación que creó problemas logísticos considerables para la empresa de ingeniería, pero que al menos evitó una explosión del tipo de conflicto social que notoria (y costosamente) bloquea el progreso de tales proyectos. 


\section{Conclusiones: cimentar lo material y lo social}

He argumentado que el concreto, una sustancia que une y fija, es una forma de materia con un potencial manifiesto para la transformación tanto social como material. Es un material que también combina las cualidades del agua con las de la piedra, siendo capaz de amoldarse y adaptarse a cualquier forma. Sin embargo, a diferencia del agua, el concreto se endurece. Su fluidez y capacidad de adaptación es sólo temporal. También he discutido cómo las combinaciones y purificaciones, que son intrínsecas al proceso de elaboración del concreto, implican orientaciones ontológicas particulares en relación con la materia. En la etnografía andina, la distinción crucial en juego está en relación con la tierra misma (los minerales, arcillas, rocas y arenas que constituyen la tierra) con respecto a las concepciones divergentes entre la vitalidad y la materia inerte. En el contexto de las obras públicas patrocinadas por el estado que se confían a las competencias de la ingeniería profesional moderna, el concreto ofrece un material fiable, previsible, flexible y resistente, perfectamente adaptado al moldeado del espacio genérico y homogéneo de una red de carreteras nacionales, un espacio que en su propia materialidad conecta una población dispar y dispersa. Y no hay duda de que este escenario se logra de alguna manera. Las carreteras proporcionan superficies consistentes para viajar, de modo que los vehículos de todo el país y más allá puedan moverse, a gran velocidad, sin tener que adaptarse de ninguna manera particular al paisaje local. Y las carreteras canalizan los flujos, para bien o para mal, dirigiendo y ordenando las principales líneas de comercio, los sitios de regulación, los asentamientos que crecen para servir a este movimiento.

Sin embargo, como es claramente evidente, si bien el concreto une y vincula realidades sociales y materiales dispares en algunos aspectos, también se caracteriza por una fragilidad fundamental en relación con su capacidad de conexión tanto en el dominio material como en el social. La singularidad del concreto se interrumpe fácilmente: es vulnerable al agua, a la temperatura, a las cargas pesadas y al abandono. También es excepcionalmente inflexible y quebradizo, y su fuerza se convierte en una debilidad con el tiempo. A medida que la tierra continúa moviéndose y creciendo debajo y alrededor de ella, la piedra líquida, ya fraguada, no puede adaptarse o crecer con ella. Aunque contiene tierra, el concreto no es de la tierra, y en ese sentido, a diferencia de ésta, no está vivo. Para algunos, esta es la razón por la que el concreto es importante. Ofrece resistencia a la especificidad de las condiciones locales, pero solo si se mantiene y respalda adecuadamente. Para otros, existe la esperanza de que el concreto pueda, a través de la negligencia, integrarse todavía 
más al paisaje general, pero, de manera crucial, solo en la medida en que se vuelva inútil como un espacio genérico. A través del abandono y la recuperación, el material podría integrarse con la tierra viva que lo rodea.

Los ingenieros contemporáneos de construcción de carreteras prestan considerable atención a la trama preexistente de los mundos que buscan transformar, pero su enfoque separa de manera resuelta el mundo material del mundo social. Las piedras y los suelos son llevados a los laboratorios donde son analizados, probados, modelados, modificados y vueltos a probar. Luego se sacan al mundo y se utilizan bajo una vigilancia constante. El concreto recibe atención ejemplar a este sentido: se diseñan sistemas de mantenimiento para controlar, medir y evaluar continuamente. El agua, identificada como el principal enemigo del hormigón, se desvía cuidadosamente con la inclinación y el drenaje calculados minuciosamente para garantizar su protección. Los esfuerzos para proteger el concreto de la sociedad dan como resultado todo tipo de prácticas regulatorias, incluidos los funcionarios estatales que monitorean el peso de los vehículos y la distribución de ese peso sobre los ejes para evitar el desgaste innecesario en la carretera. Los buenos ciudadanos no actúan como los "salvajes" que amenazan la integridad de la carretera de Nauta. Un enfoque etnográfico del proceso de construcción revela así las formas en que se entrelazan las relaciones materiales y sociales (a pesar de las mejores intenciones de los planificadores técnicos), y también cómo se elaboran arreglos tensos y en fricción entre las nociones divergentes de los órdenes material y social (Tsing, 2005).

Seguir la acción de esta sustancia revela varios tipos de discontinuidad escalar, como por ejemplo entre las promesas y los límites de la modernidad; las potencialidades de los arreglos materiales y sociales y las realidades que producen; las superficies y apariencias de las cosas, y las condiciones subyacentes que las sostienen o perturban. Esta atención etnográfica al concreto también revela fracturas en el orden social del estado, específicamente, los conflictos entre los dominios del gobierno nacional, regional y local, así como los límites de la soberanía estatal en relación con los flujos de capital, personas, ideas y materiales que no respetan o incluso no reconocen las fronteras nacionales.

En la ingeniería del espacio público, el concreto es cooptado como un importante aliado material en el negocio, altamente riesgoso, de ordenar el mundo; pero en la práctica también pone a los ingenieros frente a las fracturas y disyunciones escalares que la planificación modernista normalmente no tiene en cuenta. Es en la negociación de estas tensiones -entre la fijeza y la fluidez, entre materiales genéricos y específicos, entre 
materia autónoma y relacional- que el concreto nos ofrece una forma de pensar sobre la sociedad, la estética y el estado. Los ingenieros se ven arrastrados a negociaciones pragmáticas entre las condiciones materiales y sociales específicas, y los principios generales que motivan y estructuran sus intentos de comprometerse con la especificidad. La promesa del concreto de operar como un material genérico, homogéneo y, sobre todo, predecible, se ve constantemente desafiado por la especificidad de los terrenos a los que se aplica: terrenos que son intrínsecamente inestables y heterogéneos. La imagen de poder que ofrece el hormigón está, por lo tanto, comprometida, ya que la estabilidad y la previsibilidad de este material sólo son seguras en la medida en que está rodeado e integrado en relaciones de cuidado específicas.

\section{Agradecimientos}

Agradezco a Hannah Knox por su compañía intelectual en nuestro estudio conjunto de las carreteras peruanas, y a mis amigos en Ocongate y Cusco por enseñarme tantas cosas sobre la vida en los Andes. Los seminarios en CRESC, el Departamento de Antropología de la Universidad de California, Davis, y el Departamento de Sociología en Lancaster fueron muy útiles. Agradezco especialmente a Marisol de la Cadena, Amanda Ravetz y Celia Lury por su apoyo e inspiración, y a Celia Blondet, que continúa presentándome al Perú y que me ayudó a pensar sobre el concreto y el estado de una manera nueva.

\section{Referencias bibliográficas}

Allen, C.J. (1997). When Pebbles Move Mountains: Iconicity and Symbolism in Quechua Ritual. En R. Howard-Malverde (ed.), Creating Context in Andean Cultures (pp. 73-84). Oxford: Oxford University Press.

Bensaude-Vincent, B. y Stengers, I. (1996). A History of Chemistry (Trad. D. van Dam). Cambridge, MA: Harvard University Press.

Cohen, J. y Moeller, M. (eds.). (2006). Liquid Stone: New Architecture in Concrete. New York: Princeton Architectural Press.

Coke, J. (1999). President's Memo: South America Visit, American Concrete Industry, 24 de febrero de 2009. Recuperado de http://www.concrete.org/about/ab_presmemo_ coke11.htm.

Colloredo-Mansfeld, R. (1994). Architectural Conspicuous Consumption and Economic Change in the Andes. American Anthropologist, 96(4), 845-865.

Dumez, H. y Jeunemaitre, A. (1998). The Unlikely Encounter between Economics and a Market: The Case of the Cement Industry. En M. Callon (ed.), The Laws of the Markets (pp. 222-243). Oxford: Basic Blackwell. 
Gandy, M. (2002). Concrete and Clay: Reworking Nature in New York City. Cambridge, MA: MIT Press.

Gose, P. (1994). Deathly Waters and Hungry Mountains: Agrarian Ritual and Class Formation in an Andean Town. Toronto: University of Toronto Press.

Gurmendi, A. (2001). The Mineral Industry of Peru. US Geological Survey Minerals Yearbook, 24 de febrero de 2009. Recuperado de http://minerals.usgs.gov/minerals/pubs/ country/2001/pemyb01.pdf.

Harvey, P. (1997). Peruvian Independence Day: Ritual, Memory, and the Erasure of Narrative. En R. Howard-Malverde (ed.), Creating Context in Andean Cultures (pp. 21-44). Oxford: Oxford University Press.

Harvey, P. y Knox, H. (2009). Abstraction, Materiality and the 'Science of the Concrete' in Engineering Practice. En T. Bennett y P. Joyce (eds.), Material Powers: Cultural Studies, History and the Material Turn (pp. 124-141). London: Routledge.

Jones, P. (2006). Ove Arup: Masterbuilder of the Twentieth Century. New Haven, CT: Yale University Press.

Mukerji, C. (2006). Tacit Knowledge and Classical Technique in Seventeenth-Century France: Hydraulic Cement as Living Practice among Masons and Military Engineers. Technology and Culture, 47(4), 713-733.

Orlove, B. (1998). Down to Earth: Race and Substance in the Andes. Bulletin of Latin American Research, 17(2), 207-222.

Tafunell, X. (2007). On the Origins of ISI: The Latin American Cement Industry, 1900- 30. Journal of Latin American Studies, (39), 299-328.

Taussig, M. ([2004]2013). Mi museo de la cocaína (Gnecco, C., Trad.). Popayán, Cauca: Universidad del Cauca.

Tsing, A. (2005). Friction: An Ethnography of Global Connection. Princeton, NJ: Princeton University Press.

Wagenaar, C. y Dings, M. (eds). (2005). Ideals in Concrete: Exploring Central and Eastern Europe. Rotterdam: NAi Publishers. 